\title{
O processo de descentralização intramunicipal em São Paulo
} intramunicipal em São Paulo

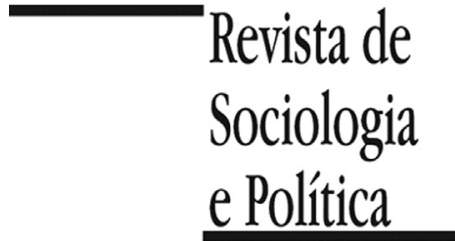

DOI 10.1590/1678-987320287501

\author{
Rony Coelho' (ip \\ 'Programa de Pós-Graduação em Ciência Política, Universidade Estadual de Campinas, Campinas, SP, Brasil.
}

RESUMO Introdução: As gestões de grandes centros urbanos têm se tornado um crescente desafio contemporâneo. Em São Paulo, problemas estruturais desde longa data deixaram marcas profundas e indeléveis no seu tecido socioespacial. Visando um modelo político-administrativo para um território de alta complexidade, foi consubstanciada na Lei Orgânica do Município, de 1990, a decisão de descentralizar a gestão municipal. Este artigo tem por objetivo examinar o processo de implementação da descentralização intramunicipal na capital paulista em suas dimensões política, administrativa e orçamentária. Para tanto, analisa os mecanismos criados para a gestão territorial, estendendo a análise até a última gestão finalizada na cidade, a de Haddad (2013-16). Materiais e métodos: A pesquisa é qualitativa e adota como perspectiva teórico-metodológica a "análise processual", segundo a qual a descentralização é um conjunto de medidas e reformas adotadas em camadas ao longo tempo. Recorre principalmente à análise documental (legislação) e a referências bibliográficas, que, aliás, mostram-se carentes em relação ao tema. Procura adaptar, heuristicamente, os termos do debate sobre descentralização dos níveis nacionais/subnacionais para os municipais/intramunicipais de forma a contemplar o caso analisado. Resultados: As evidências encontradas sugerem uma longa e desvairada trajetória do processo de descentralização na capital paulista. Portanto, não se aplica o "efeito catraca" descrito na literatura, em que as várias dimensões ou camadas dos processos de descentralização se dão de forma sequencial e seguindo uma mesma direção a cada nova rodada. Devido a um processo não consensual entre as consecutivas gestões executivas municipais sobre quais deveriam ser os papeis dos órgãos submunicipais, o processo de descentralização tem enfrentado várias reviravoltas. Discussão: $\mathrm{O}$ artigo busca somar esforços à ampliação do conhecimento sobre o processo de gestão submunicipal na maior cidade da América Latina, especialmente ao empenhar-se em operacionalizar uma análise longitudinal de médio alcance, e ao ariscar, em diálogo com a literatura tanto nacional quanto internacional, uma definição para a noção de descentralização intramunicipal, ainda que a pesquisa seja incipiente.

PALAVRAS-CHAVE: descentralização intramunicipal; governança submunicipal; gestão municipal; São Paulo; subprefeituras.

Recebido em 29 de Janeiro de 2019. Aprovado em 26 de Fevereiro de 2020. Aceito em 29 de Maio de 2020.

\section{Introdução ${ }^{1}$}

\footnotetext{
${ }^{1} \mathrm{O}$ artigo tem como base o Capítulo 1 da tese defendida pelo autor (Coelho, 2017) e foi elaborado durante o Programa de Estágio Pós-doutoral no Institute of Development Studies, University of Sussex (UK), financiando pelo CAPES (Processo: 88881.170110/2018-01). O autor agradece ambas as instituições e, especialmente, à Alex Shankland, que tornou possível o processo. É grato também aos comentários e sugestões dos pareceristas anônimos da Revista de Sociologia e Política.
}

$\mathrm{P}$ elo menos desde o último quartel do século XX, São Paulo tem sido marcada por constantes e intensas transformações. Algumas das características registradas pelas pesquisas pioneiras sobre as dinâmicas socioeconômicas, espaciais e políticas da capital paulista, especialmente aquelas realizadas no decorrer dos anos 1970, sofreram mutações desde a passagem do século. Essas mutações se deram tanto do ponto de vista empírico, dadas as transformações concretas no tecido urbano e as novas lentes metodológicas utilizadas para observá-lo, quanto do teórico/normativo, dadas as ressignificações conceituais dos estudos desenvolvidos mais recentemente.

Com efeito, ao mesmo tempo em que persistem diversos impasses antigos e estruturais, tais como as "espoliações urbanas" (Kowarick, 1979) ou os processos de periferização (Bonduki \& Rolnik, 1982), surgem problemas relativamente novos como os da crescente violência, da degradação socioambiental e os desafios da mobilidade viária, bem como do transporte público, entre outros inumeráveis percalços que assolam o cotidiano das pessoas. Como colocado pelos estudiosos da metrópole, tais fenômenos têm ocorrido em dinâmicas que vêm "deslocando" e "recolocando" as desigualdades e as injustiças sociais em um ambiente de crescente heterogeneidade (Kowarick \& Marques, 2011). Essa 
perspectiva aponta para a alta complexidade dos objetos de estudo circunscritos à capital paulista.

Há décadas, um imenso arcabouço de pesquisas interdisciplinares busca aprofundar o conhecimento sobre os mais diversos aspectos desse território multifacetado onde vivem mais de 12 milhões de habitantes, assim como das suas transformações ao longo do tempo. O estudo de Moya (2011), por exemplo, oferece um excelente panorama desse legado. Nele, a autora fornece uma intensa retrospectiva dos trabalhos intelectuais sobre a metrópole, resgatando desde os pioneiros até os mais atuais. No entanto, apesar da crescente produção dos últimos anos, conforme se depreende da leitura de Moya (e de outros, como será visto), ainda são escassas as investigações sobre o processo de descentralização de São Paulo, e praticamente inexistente aquelas que buscam realizar uma análise longitudinal de médio alcance.

Pode-se objetar, por um lado, que a carência desses estudos guarda estreita sintonia com a fragilidade do objeto empírico, isto é, das "unidades sub-municipais", para usar uma terminologia emprestada de Hlepas et al. (2018b). Afinal, como precisamente apontaram Kowarick e Marques, "a cidade se ressente fortemente de políticas de gestão efetiva do território que possam influenciar os padrões de segregação social no espaço” (2011, p. 15). E, não sem razão, Sposati (2001) caracterizou São Paulo como uma "cidade em pedaços", ao analisar as distintas divisões político-administrativas que transpassam sua área geográfica, o que revelou alta fragmentação no oferecimento de serviços e equipamentos públicos e, consequentemente, dificuldades na gestão socioespacial. Por outro lado, do ponto de vista teórico, o tema da descentralização intramunicipal tem encontrado dificuldade para firmar-se como agenda de pesquisa. O que se dá, no caso Brasil especificamente, em parte devido às poucas experiências empíricas (ainda mais raras são as bem-sucedidas), e em parte devido ao tema da descentralização ser nacional e internacionalmente dominado pelos debates sobre os planos nacionais-subnacionais, que são mais abundantes e antigos.

A despeito de tais limitações, recentemente tem surgido obras de maior vulto a examinar os processos intramunicipais, tais como o livro "Descentralização intramunicipal nas capitais brasileiras...", organizado por pesquisadores da Fundação Getúlio Vargas (Grin et al., 2018); embora se possa dizer que, no caso de São Paulo, existe bibliografia que remonta às décadas anteriores, conforme será visto. Ademais, esse debate tem ganhado fôlego renovado com investigações sobre as grandes cidades na América Latina (Grin, Bonivento \& Abrucio, 2017) e na Europa (Hlepas et al., 2018a), o que revela a importância e atualidade do assunto em um contexto no qual cada vez mais as gestões dos grandes centros urbanos (Castells \& Borja, 1996), e a reivindicação do direito à cidade (Harvey, 2012), têm se tornado um crescente desafio contemporâneo.

Ao investigar o modelo do processo de descentralização em São Paulo em suas dimensões política, administrativa e financeira, este artigo pretende contribuir com esse debate enquanto um primeiro e modesto esforço deste autor ${ }^{2}$. A concepção de descentralização intramunicipal adotada é inspirada e se aproxima de outras presentes na literatura e, ao mesmo tempo, da ideia mais ou menos correlata de governança submunicipal. Trata-se da transferência ou delegação de poder decisório, atribuições e funções, dentro de limites e circunscrições estabelecidas, das unidades centrais da gestão municipal para as unidades submunicipais. A pesquisa tem como marco inicial a Lei Orgânica do Município (LOM), de 1990, que consubstanciou a decisão de descentralizar a gestão municipal, e analisa os mecanismos criados para tanto. Isso inclui as Subprefeituras, instituídas em 2002, e os respectivos mecanismos designados para controle local, quer dizer, os conselhos participativos desses entes submunicipais 
estabelecidos em 2013. O marco temporal é o fim do governo de Fernando Haddad (PT, 2013-2016). Recorre a fontes diversas adotando como perspectiva metodológica a "análise processual" tal qual sugerida e desenvolvida por Túlia Falleti (2006).

Segundo a pesquisadora, que investiga casos nos planos nacionais-subnacionais, a descentralização deve ser concebida como um processo de reformas das políticas governamentais e a teoria deve preocupar-se em analisar "os efeitos da sequência em que as diferentes políticas descentralizadoras desdobram-se ao longo do tempo" (Falleti, 2006, p. 60). Adaptando, heuristicamente, os termos do debate para o nível local-sublocal, argumenta-se que as evidências encontradas sugerem uma longa e desvairada trajetória do processo de descentralização na capital paulista. A sequência errática deve-se às políticas não consensuais adotadas pelas distintas gestões executivas municipais - as quais foram encabeçadas por diferentes partidos políticos que administraram a cidade - sobre quais deveriam ser os papeis dos órgãos regionais submunicipais. Portanto, não se aplica ao caso o "efeito catraca" descrito por Falleti (2006), conforme será discutido e demonstrado.

Além dessa introdução, o artigo encontra-se dividido em mais quatro partes. Na segunda, procura lançar as bases teóricas da análise, demonstrando como a literatura acadêmica tem abordado a discussão da descentralização intramunicipal. Na terceira, analisa os fundamentos e a proposta de descentralização em São Paulo. Na quarta, o processo de criação das unidades de gestão submunicipais e as dimensões da descentralização ao longo do tempo. Por fim, o artigo se encerra com breves considerações dos problemas investigados e suas implicações analíticas, bem como dos seus possíveis desdobramentos.

\section{Descentralização intramunicipal: conceitualização e adaptação dos termos dos debates}

${ }^{3}$ Essa alegação é corroborada por Grin et al. (2018, p. 288), que assinalam: esse "é um campo recente de estudo. [...] basta observar a literatura utilizada pelos autores de cada capítulo desse livro, pois são poucas as pesquisas e trabalhos existentes sobre cada cidade". De fato, excluindo-se os trabalhos anteriores dos autores do livro, sobram raríssimas referências ao tema.
O tema na literatura acadêmica é bastante amplo e diversificado. Na ciência política, grande parte dos trabalhos preocupa-se com os arranjos institucionais adotados e, comumente, associa as análises às dos processos de federalização e cooperação com e entre as partes subnacionais, aos arranjos dos sistemas e subsistemas políticos, aos ciclos de políticas públicas ou ao tema do desenvolvimento "local" (Sadek, 1991; Souza, 1996, 2001, 2004). As aspas aqui indicam que o local, nesses casos, é entendido como os estados ou municípios. Essa perspectiva, mais sólida e consolidada, lança desafios às análises dos processos "sub" ou "intra", terminologias mais ou menos correlatas utilizadas como referências para designar "o local" (ou, alternativamente, o sublocal) enquanto unidades em níveis inferiores aos municípios ou prefeituras. Dito de outra forma, em que pese a vasta produção existente sobre o tema da descentralização em linhas gerais, não são muitas as referências para os processos sublocais ${ }^{3}$.

O desafio de analisar a relação entre as unidades centrais municipais e as submunicipais tem sido enfrentado, por um lado, com a adaptação dos termos do debate. Apesar de muitos dos elementos das discussões da descentralização não dizerem respeito diretamente a esses níveis, não é incomum o procedimento de tomar emprestadas as análises teóricas realizadas nos planos nacionais. É compartilhado, por exemplo, por Grin e colegas (2018, p. 17), que assinalam: "ressalvando-se as diferenças, pois Estados e municípios são entes governamentais, ao passo que as divisões administrativas e territoriais nas cidades não têm esse status legal, considera-se que os argumentos são válidos para a discussão da descentralização intramunicipal". Também Borja (1984), em texto clássico sobre a temática, havia registrado que suas reflexões se aplicam tanto ao Estado como às grandes cidades ou governos metropolitanos. 
Por outro lado, com o destaque que vem ganhando o tema da gestão dos grandes centros urbanos, a investigação sobre os seus modelos político-administrativos tem recebido atenção e produzido análises próprias. O livro de Hlepas et al. (2018a) é uma amostra dessa literatura que analisa com afinco diversas cidades da Europa valendo-se do conceito de governança submunicipal. Grin, Bonivento e Abrucio (2017) lançam olhar que vislumbra comparação entre metrópoles da América Latina, tais quais Medelin, Bogotá, Quito, Cidade do México, Buenos Aires, Lima, São Paulo e Rio de Janeiro. Outra publicação recente, já mencionada (Grin et al., 2018), analisa de forma pioneira a descentralização em oito capitais brasileiras, buscando preencher uma lacuna comparativa nacional que até então só se encontrava em esforços esparsos (Boshi, 1999; Martinelli \& Olivieri, 2015; Grin, Lameirão \& Bessa, 2015).

Nessa esteira, faz-se necessário mencionar que, para o caso específico da descentralização em São Paulo, o tema não é novo (Scarfoni Filho, 1981) e boa parte das produções estão localizadas no interstício entre a promulgação da LOM (1990) e a lei de aprovação das Subprefeituras (2002) (Keinert, 1993; Di Giussepe, 1998; Martins, 1997; Caccia Bava, 1999; Calderón, 2000; Calderón \& Chaia, 2002). Outra parte considerável foi produzida no momento imediatamente posterior ao estabelecimento dos órgãos regionais, analisando seus processos de proposição e tramitação (enquanto projeto de lei) bem como de sua implementação durante o governo Marta Suplicy (PT, 2001-2004) (Garibe \& Capucci, 2004; Santos \& Barreta, 2004; Finatec, 2004; Pólo et al., 2005; Grin, 2011, 2015); com raras exceções se dedicando ao período mais recente (Grin, 2018).

A bibliografia supracitada tem produzido definições e delimitações fundamentais ao tema da descentralização intramunicipal. Antes de tudo, convém observar, corroborando o sugerido por Grin et al. (2018, p. 16), que "o termo 'intramunicipal' engloba as questões administrativas, políticas e financeiras inseridas na auto-organização municipal". Em linhas gerais, essa modalidade de descentralização pode ser entendida como "a transferência de atribuições do governo municipal para as unidades distritais" (Ferreira, Borges \& Ferreira, 2018, p. 242) ou, para tornar mais generalizável, como a transferência de atribuições do governo municipal para as unidades submunicipais, que podem assumir formatos diversos (Hlepas et al., 2018b). Sob o viés de Lameirão, Cunha e Torres (2018, p. 116), também é possível caracterizar o processo como a "transferência efetiva de poder decisório para os agentes locais da administração municipal, em que se outorga aos órgãos regionais autonomia". Os autores acrescentam que essa autonomia deve se dar dentro de limites estabelecidos para formular políticas locais e que não se confundiria "com um conjunto de ações e iniciativas realizadas pela gestão municipal para desburocratizar e melhorar o atendimento e os serviços prestados à população" (2018, p. 135). Dito de outro modo, não se confundiria com a simples desconcentração geográfica das atividades para fins de execução, dissociada das atividades de planejamento e tomada de decisão (Scarfoni Filho, 1981).

Também há na literatura internacional acepções correlatas a essas noções de descentralização (intra-municipal decentralisation), tal como designadas por Van Ostaaijen, Gianoli e Coulson (2012) e Swianiewicz (2015). Esses autores basicamente a definem como uma combinação particular de descentralização e democratização direcionada a fortalecer a interação entre os agentes municipais e os cidadãos, ao estabelecer instituições e funções de entregas de serviços no nível submunicipal. Ou seja, de forma sumarizada e como uma tentativa de conceituação, pode-se entender o processo de descentralização intramunicipal como um conjunto de medidas adotadas visando a transferência ou delegação de poder de decisão, atribuições e funções, dentro de limites legais e circunscrições territoriais estabelecidas, das unidades centrais da gestão para as unidades 
submunicipais, englobando as dimensões política, administrativa, financeira e de controle social.

Essa "governança" no nível submunicipal traria benefícios como as racionalidades cívicas, sociais, políticas e econômicas, tal qual assinalado por autores como Hlepas et al. (2018b), Swianiewicz (2015) e Lowndess e Sullivan (2008). É conveniente observar que tais racionalidades, em grande medida, estão em consonância com os argumentos mais ou menos consensuais de grande parte das defesas (ou dos ideais) das gestões descentralizadas. A primeira diz respeito a possibilidade do aumento da participação dos cidadãos - no limite, por auto interesse - e do resgate do censo de comunidade, subjazendo as noções da construção de capital social, do fortalecimento dos laços sociais, e das sociabilidades baseadas no princípio da proximidade, para a promoção da ação coletiva voltada aos interesses locais. A racionalidade social se refere aos "saberes locais" e às preferências e necessidades dos moradores de determinadas localidades. Afinal, argumenta-se, problemas enfrentados no cotidiano seriam mais perceptíveis pelos pertencentes ao território. Suas resoluções, por sua vez, frequentemente perpassam pelos conhecimentos locais. Já a política é associada à noção de "democracia local", uma vez que os cidadãos, pelo princípio da proximidade, teriam incentivos a participar do governo local pois teriam maior acessibilidade e facilidade, podendo responsabilizar os políticos diretamente por suas ações e omissões, promovendo, assim, maior controle social e accountability. Os líderes ou políticos locais, por seu turno, estariam mais sujeitos à pressão nesse âmbito e teriam maior inclinação a responder às demandas populares, sendo mais responsivos. Por fim, a racionalidade econômica, refere-se aos princípios da eficiência na aplicação dos recursos disponíveis, desde que observada a economia de escala, uma vez que poderiam ser aproveitadas as fontes, a sinergia e a criatividade local de forma flexível na resolução dos problemas.

Enfim, como enfatizam Lowndess e Sullivan (2008), essas racionalidades intrinsicamente interligadas muitas vezes podem ser apenas distinguidas analiticamente. Não obstante, se esses seriam os benefícios da gestão submunicipal, na contraface da moeda desse ideal encontram-se seus "efeitos perversos". Ou, como sugere um grande historiador francês citado por Arretche, os "efeitos perversos da proximidade" (Rosanvalon, 1993 apud Arretche, 1996, p. 19). Como se sabe, a questão da descentralização e "poder local" é bastante complexa. Conforme assinalado por Nunes (1996, p. 34), a "proximidade do poder [local] é no mínimo ambígua, pois é também o lugar da reprodução do poder discricionário das oligarquias", o que é particularmente marcante para o caso brasileiro assolado por uma cultura política baseada em relações personalistas; clientelistas, patronais ou coronelistas, para usarmos apenas alguns poucos termos associados a essa tradição. Na verdade, os efeitos perversos ou ao menos a ambiguidade da proximidade não é o único fator negativo a depor contra os supostos benefícios da governança local. Como ressaltou Souza (1996, p. 105), se quisermos, "para cada princípio a favor da descentralização, pode-se igualmente identificar outro que o contrarie". Mas não é o caso de estender demasiado essa infindável discussão aqui.

Para contornar o impasse, no entanto, é prudente observar que o conceito de descentralização traz embutido a capacidade de prometer mais do que se pode cumprir. Portanto, é "fundamental refletir sobre a descentralização a partir de experiências concretas". Ou seja, se o conceito de descentralização pode ser "vago e ambíguo", é preciso considerar que, para além dos seus princípios e postulados teóricos, a descentralização também é processo concreto, empiricamente verificável, que se dá a partir de decisões e ações de atores políticos e sociais (Souza, 1996, p. 104-106). No caso de São Paulo, por exemplo, a decisão de descentralizar a gestão municipal foi cravada na sua "constituição 
municipal" e, posteriormente, ações para efetivá-la foram tomadas, diga-se de passagem, não sem conflitos. Muito pelo contrário.

Para analisar o caso concreto, alguns elementos teóricos de trabalhos como os de Falleti (2006), Shah e Thompson (2004) e Arretche, Vazques e Gomes (2012), combinados e com a adaptação dos termos, podem oferecer um caminho interessante. Falleti (2006) desenvolve uma "teoria sequencial da descentralização" cujos princípios são que: i) a descentralização deve ser concebida como um processo de reformas das políticas governamentais; ii) deve-se levar em consideração os interesses territoriais (locais); iii) ao analista cabe averiguar como os efeitos da sequência desdobram-se ao longo do tempo. Subjaz a essa perspectiva a noção de trajetória dependente (path dependent) que, grosso modo, advoga que decisões tomadas em determinada circunstância são limitadas ou constrangidas por aquelas tomadas no passado. Essa "teoria sequencial" encontra correspondência com a modalidade gradual de implementação (gradual approach) descrita por Shah e Thompson (2004). Os autores também entendem a descentralização como um conjunto de reformas e sugerem que ela pode se dar de forma acelerada ou gradual. No primeiro caso, que denominam de abordagem "big bang" (big bang approach), a implementação se daria por uma única iniciativa e em um curto espaço de tempo. Em contraste, a segunda abordagem seria gradual e sequencial, adotada em pequenos passos e, portanto, dilatada temporalmente. Como veremos, esse foi o caso previsto para a implementação das Subprefeituras em São Paulo.

Arretche, Vazques e Gomes (2012, p. 31) definiram e analisaram as dimensões das medidas adotadas. De maneira concisa e direta, a dimensão política seria relativa "à possibilidade de que os governos locais sejam eleitos diretamente e tenham um mandato próprio" e, portanto, irrevogável pelos níveis superiores. Conforme a definição de descentralização intramunicipal acima trabalhada, é válido aqui explicitar que essa dimensão inclui também o controle social. A dimensão fiscal seria "relativa à autoridade dos governos locais sobre suas próprias receitas", à autoridade de gerá-las e/ou administrá-las autonomamente. Por fim, a dimensão administrativa, de competências ou atribuições, seria aquela "relativa à responsabilidade pela execução de políticas públicas".

Com os elementos aventados, é possível analisar o processo de descentralização na capital paulista sob suas dimensões política, fiscal e administrativa a partir das seguintes questões: como tem se dado o processo de escolha dos subprefeitos? E o controle social nessas unidades submunicipais? Quais competências têm sido atribuídas às Subprefeituras? Quanto recurso orçamentário tem sido destinado a esses entes sublocais? Embora relativamente simples, essas questões permitem analisar o modelo de implementação da descentralização intramunicipal em São Paulo à luz da teoria examinada.

\section{A proposta de descentralização em São Paulo}

Com o pacto federativo alcançado na Constituição Federal de 1988, muitos consideraram, à época, que os municípios foram bastante beneficiados. Em primeiro lugar, porque esses novos entes federados ampliaram sua participação na receita disponível, em que pesem os posteriores e hodiernos desafios enfrentados por muitas localidades em relação à capacidade de estabelecer formas próprias de arrecadação, bem como à chamada "guerra fiscal". Em segundo lugar, a Carta Magna os tornou autônomos já que cada um passou a ter o direito de promulgar suas próprias "constituições municipais", as leis orgânicas (Sadek, 1991; Souza, 1996). Com isso, os municípios puderam estabelecer muitas das suas diretrizes de gestão. 
Dada tal autonomia, em São Paulo, uma das primeiras ações tomadas no sentido da descentralização foi estabelecer em sua Lei Orgânica a criação das Subprefeituras. Naquela altura, no início dos anos 1990, a cidade já contava com quase 10 milhões de habitantes e muitos dos desafios da gestão territorial já se apresentavam como problemas estruturais da malha urbana. Na verdade, as primeiras iniciativas de desconcentração da prestação de serviços foram tomadas desde o começo da explosão demográfica, da intensificação da urbanização e do crescimento desordenado, cujo início coincidiu mais ou menos com o interregno democrático de 1946-1964. Na década de 1950, criaram-se os núcleos administrativos regionais designados como distritos de obras e posteriormente chamados de Administrações Regionais (ARs) (Scarfone Filho, 1981). Como descreve Di Giussepe (1998, p. 53), "o modelo previa o planejamento centralizado com execução desconcentrada das atividades administrativas", visando maior agilidade na execução. Não possuíam, portanto, qualquer tipo de autonomia, não realizando mais do que pequenos serviços urbanos.

São Paulo possui uma área socioespacial heterogênea e multifacetada, cujas dinâmicas socioeconômicas, culturais e políticas são altamente complexas. Visando um modelo de gestão que poderia dar conta de um território com essas características, e seguindo uma tendência mundial nos grandes centros urbanos, em 1990 os constituintes municipais estabeleceram a descentralização em diversos artigos da LOM (arts. 56; 75-80). Usando a metáfora de Sposati (2001), procurou-se um modelo de gestão para os "pedaços" da cidade na "cidade em pedaços".

Em uma das principais pesquisas realizadas sobre a elaboração da LOM, que analisa suas diversas fases através dos Anais da Assembleia Municipal Constituinte (AMC), Calderón (2000) procura demonstrar como as Subprefeituras foram aprovadas e inseridas na constituição municipal como uma das diretrizes estruturantes da gestão territorial, visando suplantar as então existentes ARs. Essas últimas funcionavam, no melhor dos casos, como distritos de obras para a realização de pequenos serviços de rotina e obras de manutenção urbana e, no pior, como nichos de corrupção. Calderón (2000, p. 84) enfatiza que, durante a fase de apresentação de propostas à AMC, buscando superar as relações "fisiológicas" estabelecidas nesses órgãos, "o PSDB apresentou um projeto que visava eliminar os desvios existentes na escolha dos administradores regionais".

Conforme a concepção original, o território seria subdividido em Subprefeituras e, em cada uma delas deveria existir um Conselho de Representantes composto por moradores dos bairros dentro de sua jurisdição. O projeto, então encaminhado pelo PSDB, foi acatado, nas palavras de Calderón, por todos os "partidos progressistas", incluídos o PT, PCB, PCdoB, PV e PDT. Antes mesmo da votação no Plenário, ainda na Comissão de Sistematização das propostas, "a luta pela criação das Subprefeituras e dos Conselhos de Representantes deixou de ser um patrimônio do PSDB, passando a constituir-se uma bandeira dos setores progressistas da Câmara. Todos os partidos progressistas apresentaram sugestões para aprimorar essa proposta" (Calderón, 2000, p. 118).

Como seria de se esperar, com o avanço das diversas fases da AMC houve modificações em relação ao projeto inicial, sendo o texto final aprovado sem grandes resistências, seguindo o "espírito da época". Ao fim e ao cabo, a LOM estabeleceu que "o Poder Executivo é exercido pelo Prefeito, auxiliado pelos Secretários Municipais e pelos Subprefeitos" (art. 56) e que "a administração municipal será exercida, em nível local, através de Subprefeituras" (art. 77) (São Paulo, 1990). Entretanto, a aprovação sob certo consenso das "unidades submunicipais de gestão" não significou que não existiram divergências, as 
quais se deram, principalmente, em relação ao modo de recrutamento dos subprefeitos, isto é, em relação à dimensão política da descentralização.

Por exemplo, o projeto original previa que os administradores regionais de cada Subprefeitura deveriam ser indicados pelo prefeito aos Conselhos de Representantes, e que a nomeação somente se daria sob a aprovação desse colegiado (Calderón, 2000, p. 22-23). Porém, o que permaneceu no texto final é bastante distinto disso, e um tanto ambíguo. Ao passo que o art. 76 da LOM estabelece que "os secretários municipais e os subprefeitos serão nomeados pelo prefeito", o art. 77 subscreve (não mencionando os secretários) que "o processo de escolha do subprefeito será definido na forma estabelecida em lei". Ou seja, um artigo sugere o processo de escolha e o outro o deixa em aberto. Posteriormente, essa ambivalência permitiu que a lei de regulamentação das Subprefeituras prescrevesse em seu art. $8^{\circ}$ que "os cargos dos subprefeitos serão de livre nomeação pela prefeita" (São Paulo, 2002); e que, em 2016, Haddad enviasse um projeto de lei do Executivo à Câmara dos Vereadores propondo a modificação da referida lei de 2002 para instituir, previamente à nomeação pelo prefeito, a eleição direta para subprefeito, com voto facultativo em cada uma das Subprefeituras (São Paulo, 2016).

A LOM igualou subprefeitos e secretários municipais tornando-os auxiliares diretos do Prefeito, o que foi endossado posteriormente pela legislação que criou as Subprefeituras. Em tese, o subprefeito seria o representante local do governo com mais poder decisório se comparado aos antigos administradores regionais. Assim, pode-se dizer que, com as ARs, que vigoraram até o início dos anos 2000, havia uma desconcentração territorial na prestação de serviços, mas não uma descentralização política; não havia a transferência de qualquer tipo de autoridade do órgão central para os inferiores.

As Subprefeituras, por sua vez, foram concebidas como "unidades administrativas com capacidade de decisão e autonomia financeira, com o objetivo de aproximar a administração local dos cidadãos" (Keinert, 1993, p. 75) ou, em outras palavras, como "unidades integradoras, com orçamento próprio e autonomia, responsáveis pelo planejamento e execução do conjunto de serviços, num território claramente definido" (Martins, 1997, p. 2). Em tese, o processo de descentralização consistiria em reformar as estruturas dos antigos órgãos de administração local e regulamentar as novas estruturas. Isso significaria remodelar tanto a estrutura organizacional da Prefeitura quanto dos órgãos regionais existentes até então. Afinal, o processo não se daria em um "vazio institucional". Procedimentos tais como redefinir o fluxo das informações e das operações de trabalho de diferentes setores, alocar pessoas e recursos diversos (físicos, administrativos etc.) nos novos órgãos, e implementar novas praças de atendimento à população dependeriam de medidas de grande envergadura (Finatec, 2004). Isso para não mencionar as complexas questões da "cultura organizacional" e sua morosa mudança (Pólo et al., 2005). Tamanha complexidade exigiu que a lei de criação das Subprefeituras previsse, desde seu artigo

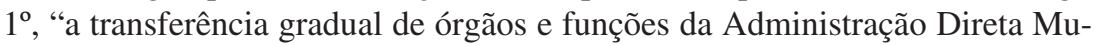
nicipal” para os órgãos submunicipais (São Paulo, 2002). O processo poderia ser considerado de médio prazo ao requerer certo "timing" para a aplicação e consolidação dessas medidas (Falleti, 2006).

A reestruturação envolveria não apenas questões técnico-administrativas, mas também políticas. À época, era corrente a avaliação de que se a descentralização fosse desencadeada de forma acelerada, sem a construção dos devidos acordos políticos, poderia fracassar em decorrência da descontinuidade dos programas, projetos ou outras ações do governo ocasionadas pelo possível acirramento dos conflitos com os atores veladamente ou diretamente resistentes às medidas tomadas. Resistências não somente externas (dos partidos de opo- 
sição), mas também internas ao próprio partido do governo à época, bem como das "estruturas atávicas" das Secretarias Municipais, conforme bem demonstra Grin em diversas oportunidades $(2011,2015)$.

De toda forma, as ARs entraram definitivamente em crise após os escândalos de corrupção que as envolveram na gestão de Celso Pitta (1997-2000) (Pinheiro, 1999). Na campanha eleitoral de 2000, os principais candidatos a prefeito se comprometeram a regulamentar as Subprefeituras (Calderón \& Chaia, 2002). Marta Suplicy (2001-2004) foi eleita e, enfim, a criação das Subprefeituras foi aprovada e o processo de implementação da descentralização intramunicipal foi iniciado.

\section{A implementação das Subprefeituras e as dimensões da descentralização}

Conforme constava no plano de governo Muda São Paulo, da então candidatura da petista Marta Suplicy, os novos órgãos seriam centros regionais com poder de decisão (apud Grin, 2011). Nas palavras de Grin (2011, p. 42), o modelo idealizado previa que "as políticas públicas locais seriam executadas de forma integrada, o que reordenaria a gestão municipal a partir das demandas locais, ao invés de ações centralizadas e setoriais".

Com a regulamentação (Lei $\mathrm{n}^{\circ}$ 13.399/02), ficou estabelecido que aos subprefeitos caberia "a decisão, direção, gestão e controle dos assuntos municipais em nível local" (art. 3) e que dentre as suas atribuições estariam as atividades de planejar, controlar e executar os sistemas locais, diretrizes e programas fixados pela instância central da administração (art. 4); e ainda, que os órgãos teriam "dotação orçamentária própria, com autonomia para a realização de despesas operacionais, administrativas e de investimento, e participação na elaboração da proposta orçamentária da prefeitura (art. 6) (São Paulo, 2002). Ou seja, endossando a Lei Orgânica do município, e compreendendo as dimensões da descentralização consideradas na literatura, a regulação das Subprefeituras previa autonomia política, administrativa e financeira para os órgãos sublocais.

Foram criadas 31 Subprefeituras e, no interior de cada uma delas, iniciando o processo de implementação, aprovadas a criação de 7 coordenadorias para executarem as políticas nos territórios. A cada uma delas caberia indicar as prioridades de sua respectiva área bem como executar as atividades e programas do governo nas distintas regiões da cidade. A partir de 2003, iniciou-se efetivamente a transferência das unidades administrativas das Secretarias Municipais para as sublocais.

Em tom crítico, Grin (2011, p. 54) afirma que "basicamente serviços e equipamentos já desconcentrados nos territórios foram repassados às Subprefeituras". Diz o autor logo na sequência, "com essas medidas se formalizaram as competências administrativas dos Subprefeitos sobre serviços já presentes nos territórios". Ainda segundo o sociólogo, a lei de 2002 aprovou a criação dos cargos nas Subprefeituras, mas não a estrutura administrativa necessária à gestão das regiões da cidade, visão que parece contrastar com a envergadura das medidas adotadas desde o início do processo. Para se ter uma noção do volume dessas ações e medidas, vale citar que, visando reformar a estrutura administrativa em um curto período, foram editados mais de 30 atos normativos, principalmente Decretos e Portarias que dispunham sobre as transferências de projetos, atividades e competências para os novos órgãos regionais, conforme Apêndice elaborado pela assessoria técnica Finatec (2004, p. 131-135), fundação responsável por auxiliar nas questões técnicas do processo.

Eduardo José Grin $(2011 ; 2013 ; 2015)$ destaca dois importantes pontos do que ele chama de "construção e desconstrução" das Subprefeituras no governo 
Suplicy. Primeiro, os cargos criados com a aprovação e implementação das Subprefeituras foram usados pelo Executivo municipal para forjar uma maioria parlamentar, franqueando a indicação dos subprefeitos aos vereadores. Para o autor, "ao aprovar as subprefeituras, o governo fez desse processo um marco para consolidar sua política de alianças no parlamento" (Grin, 2011, p. 64). Ele aponta que o processo de barganha foi notoriamente reconhecido até mesmo pelo então Secretário Municipal das Subprefeituras, Antônio Donato (PT), quando ele afirma que "o governo Marta arquitetou uma maioria parlamentar e o terreno prioritário dos acordos foi o das Subprefeituras" (Grin, 2011, p. 64).

O segundo ponto é que o modo como a descentralização foi operada implicaria a perda de poder das Secretarias Municipais, e isso gerou conflitos até mesmo dentro do próprio partido governista e das instâncias governamentais (entre os funcionários de carreira). As Secretarias temiam a autonomia das "prefeiturinhas" e a perda de controle devido à descentralização dos recursos financeiros. No jogo político, o governo operava com um cenário futuro em que, após a aprovação da Lei, haveria uma adesão das Secretarias, o que na prática se revelou uma tarefa árdua. A então recém-criada Secretaria Municipal das Subprefeituras abriu diálogo com as demais setoriais para averiguar o que seria possível transferir para os órgãos regionais. O resultado foi que as Secretarias setoriais, no geral, "buscaram justificar como deveria ser a sua organização setorial no território ou apresentaram as razões para manterem centralizadas várias atividades" (Grin, 2011, p. 49). Assim, conforme ressalta Grin, um dos efeitos não previstos da descentralização em São Paulo foi o de transformar as Secretarias, e não as Subprefeituras, nos atores-chaves do processo. Com esse "desencontro", as Secretarias setoriais, e não as Subprefeituras, é que passaram a condicionar "a forma, o conteúdo e o ritmo" do processo de descentralização. "[É] nesse sentido que a implantação das Subprefeituras foi errática, limitada em alcance administrativo e desigual na capacidade de gerir políticas públicas nas regiões" (Grin, 2011, p. 54).

Se por um lado a análise de Grin demonstra os constrangimentos enfrentados pelo governo Marta e os recuos concedidos para implementar as Subprefeituras, por outro, o autor praticamente se silencia sobre todo o passivo "caótico" - para usar um termo de Sposati (2001) - da fragmentada estrutura administrativa da capital paulista. Limita-se apenas a indicar em poucas e esparsas frases pontuais que os governos dos anos 1990, de Maluf e Pitta, eram contrários ao modelo político-administrativo descentralizado e que, portanto, não tinham interesse na implementação das Subprefeituras. É preciso considerar que os processos não se deram em um "vazio institucional". Desse modo, o problema é que Grin joga para o momento inicial da implementação todo o peso do fracasso ou da "desconstrução" das Subprefeituras. E não é só. Além de negligenciar todo o passado caótico, o autor desconsidera todo o desmonte da incipiente implementação nos governos posteriores ao da petista ${ }^{4}$.

Como não se tratava de um processo do tipo "big bang", inclusive foi previsto para ocorrer de forma gradual, é preciso atentar para o fato de que, como bem analisou Falleti (2006), processos de descentralização sequencial se dão por um conjunto de medidas adotadas ao longo do tempo, o que exige um olhar atento não apenas para o contexto mais imediato. Para processos como esse, de grande envergadura, é necessário observar a importância de análises de médio alcance longitudinal. A embrionária descentralização, iniciada com a aprovação das Subprefeituras, sofreu forte retrocesso já no início da gestão José Serra (PSDB)/ Gilberto Kassab (2005-2008).

No primeiro ano de mandato sob a gestão do PSDB/DEM, o executivo municipal tratou de "recentralizar" os serviços de saúde que haviam sido transferidos para as recém-criadas Coordenadorias locais, o que se deu, em parte, pela 
5 Valores brutos não corrigidos pela inflação. Como o que se pretende demonstrar são os valores relacionais, ou seja, a proporção do orçamento das subprefeituras em relação ao da prefeitura, não haveria diferenças em corrigir tais valores. pressão das próprias instâncias governamentais. O Decreto n ${ }^{\circ}$ 46.209/2005 "dispõe sobre a transferência das coordenadorias da saúde das Subprefeituras que especifica para a Secretaria Municipal de Saúde". O impacto de medidas como essa, editadas sucessivamente até a quase extinção das Coordenadorias, e de outras atribuições cedidas às Subprefeituras, foi o de uma vertiginosa queda no orçamento dos recém-criados órgãos administrativos regionais, como se pode visualizar no Gráfico 1.

Em 2004 e 2005, o orçamento das Subprefeituras tinha atingido, respectivamente, $20,9 \%$ e $19,4 \%$ do orçamento total da prefeitura, sendo o valor de 2003 baixo porque a implementação ainda estava em fase de planejamento (Finatec, 2004). Porém, no primeiro orçamento elaborado pela gestão Serra (em 2005, para ser executado no ano de 2006), o valor caiu para $4 \%$ do montante previsto para a prefeitura. Desde então, essa porcentagem foi caindo gradativamente e atingiu, na gestão Haddad (2013-2016), a marca relativa mínima de 2,5\%.

O orçamento da prefeitura no período considerado (Gráfico 2), em valores brutos, saltou de 10,9 bilhões, em 2003, para 56,7 bilhões em 2016, enquanto o valor bruto do orçamento das Subprefeituras ficou na média de 1,1 bilhão, com pequenas variações para cima ou para baixo ${ }^{5}$. Ou seja, o orçamento das Subprefeituras, dado a política de desmonte após o momento inicial, não acompanhou a evolução do da prefeitura.

Um interessante artigo intitulado Retrocesso na descentralização administrativa municipal (Antunes, s/d), sintetiza o que demonstram os gráficos ao elencar uma série de atribuições que foram retiradas dos órgãos submunicipais. Segundo o artigo, logo no início do governo Serra as Coordenadorias de saúde e de educação foram retiradas das Subprefeituras. Depois, os serviços de limpeza pública, que também haviam sido transferidos para as administrações locais, foram redirecionados ao órgão central. O mesmo ocorreu em relação à administração dos parques municipais, que retornou à Secretaria do Verde. O texto diz: "na área jurídica [...] o então secretário Marrey retirou das subprefeituras os raros procuradores municipais que ajudavam a agilizar ações e processos localmente", de forma que "as subprefeituras se tornaram então, carentes de assessoria e apoio jurídico". Por fim, completa: "agora, logo no início desta gestão [Kassab], novos golpes: as coordenadorias de assistência social foram extintas e as ações voltaram ao comando da Secretaria Municipal sob a batuta da vice-prefeita que acumula esse posto" (Antunes, s/d, s/p).

Como se pode depreender, o esforço inicial de reestruturação das antigas ARs em Subprefeituras não foi mantido, seja no que diz respeito à destinação de recursos (descentralização financeira) ou à desconcentração de atribuições (descentralização administrativa). Pelo contrário, sem um consenso entre os distintos partidos políticos que no período administraram a cidade sobre quais deveriam ser os papeis das Subprefeituras, assistiu-se ao desmonte do processo de descentralização antes de se consolidarem suas camadas.

Quanto à dimensão política da descentralização, para além do que Grin (2011) apontou em relação ao governo Marta, vale assinalar que nas gestões Serra/Kassab e Kassab é possível identificar dois perfis gerais distintos de indicados aos cargos de subprefeitos. Ao assumir a prefeitura, José Serra nomeou para os postos políticos aliados de fora de São Paulo, como ex-vereadores, ex-prefeitos ou correligionários que trabalhavam em órgãos públicos de outras cidades. Provavelmente Serra vislumbrava apoio político para a eleição de governador em que viria a concorrer em 2006 (da qual, aliás, saiu vitorioso). Já com Kassab, as Subprefeituras foram sendo assumidas, progressivamente, por militares aposentados. Todas as 31 Subprefeituras chegaram, em determinado momento, a serem chefiadas por agentes desse perfil. Um trecho de uma reportagem publicada no jornal Folha de S. Paulo capta o que interessa ressal- 
Gráfico 1 - Porcentagem do orçamento anual das Subprefeituras em relação ao da Prefeitura

2003

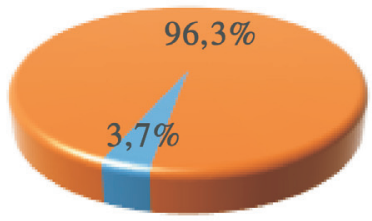

Orç. Pref: 10,5 bilhões

Orç. Sub: 396,5 milhões

\section{8}

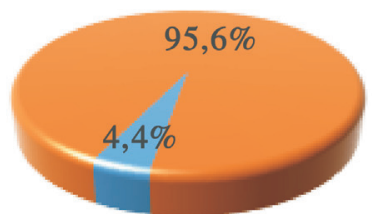

Orç. Pref: 25,2 bilhões Orç. Sub: 1,1 bilhão

2013

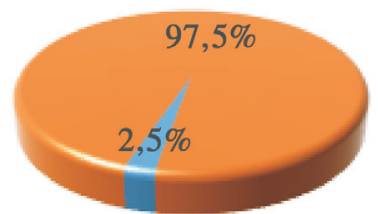

Orç. Pref: 42,0 bilhões Orç. Sub: 1,0 bilhão
2004

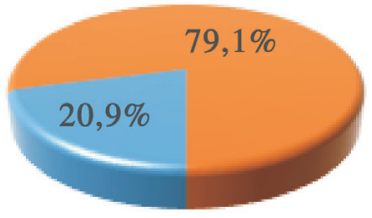

Orç. Pref: 14,2 bilhões Orç. Sub: 2,9 bilhões

\section{9}

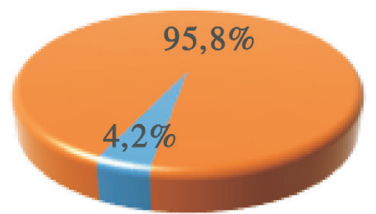

Orç. Pref: 27,6 bilhões Orç. Sub: 1,1 bilhão

2014

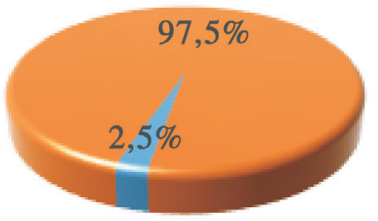

Orç. Pref: 50,5 bilhões Orç. Sub: 1,2 bilhão
2005

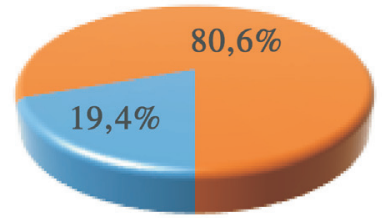

Orç. Pref: 15,2 bilhões Orç. Sub: 2,9 bilhões

2010

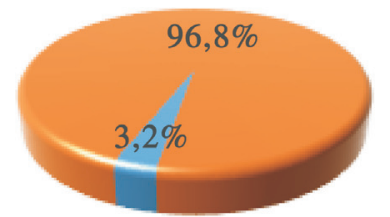

Orç. Pref: 27,8 bilhões Orç. Sub: 898,4 milhões

2015

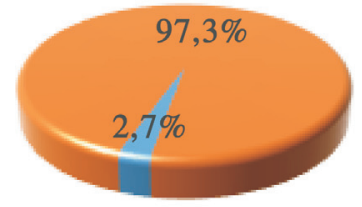

Orç. Pref: 51,3 bilhões Orç. Sub: 1,3 bilhão

2006

2007

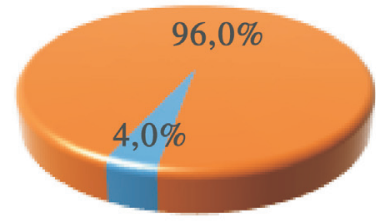

Orç. Pref: 17,2 bilhões Orç. Sub: 391,8 milhões

2011

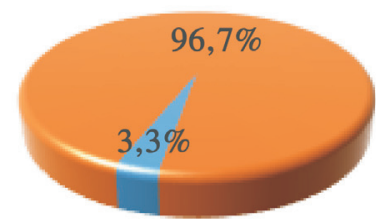

Orç. Pref: 35,6 bilhões Orç. Sub: 1,1 bilhão

2016

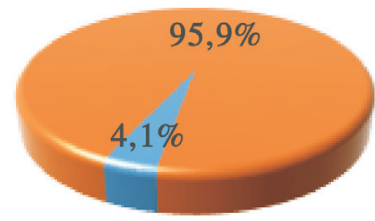

Orç. Pref: 21,5 bilhões Orç. Sub: 875,3 milhões

2012

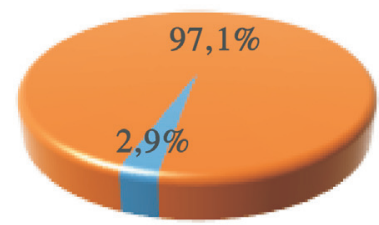

Orç. Pref: 38,7 bilhões Orç. Sub: 1,1 bilhão

Fonte: Elaboração própria a partir das “despesas previstas” nas Leis Orçamentárias Anuais (2003-2016). Disponíveis em: http://orcamento.sf.prefeitura.sp.gov.br/orcamento/loa.php. Acesso em: 15 de dez. 2020 .

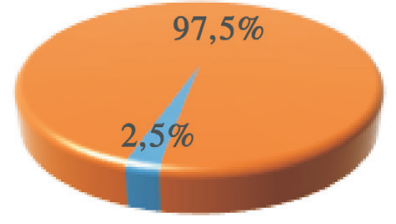

Orç. Pref: 54,4 bilhões Orç. Sub: 1,3 bilhão 
Gráfico 2 - Orçamentos anuais da Prefeitura versus os das Subprefeituras (2003-2016)
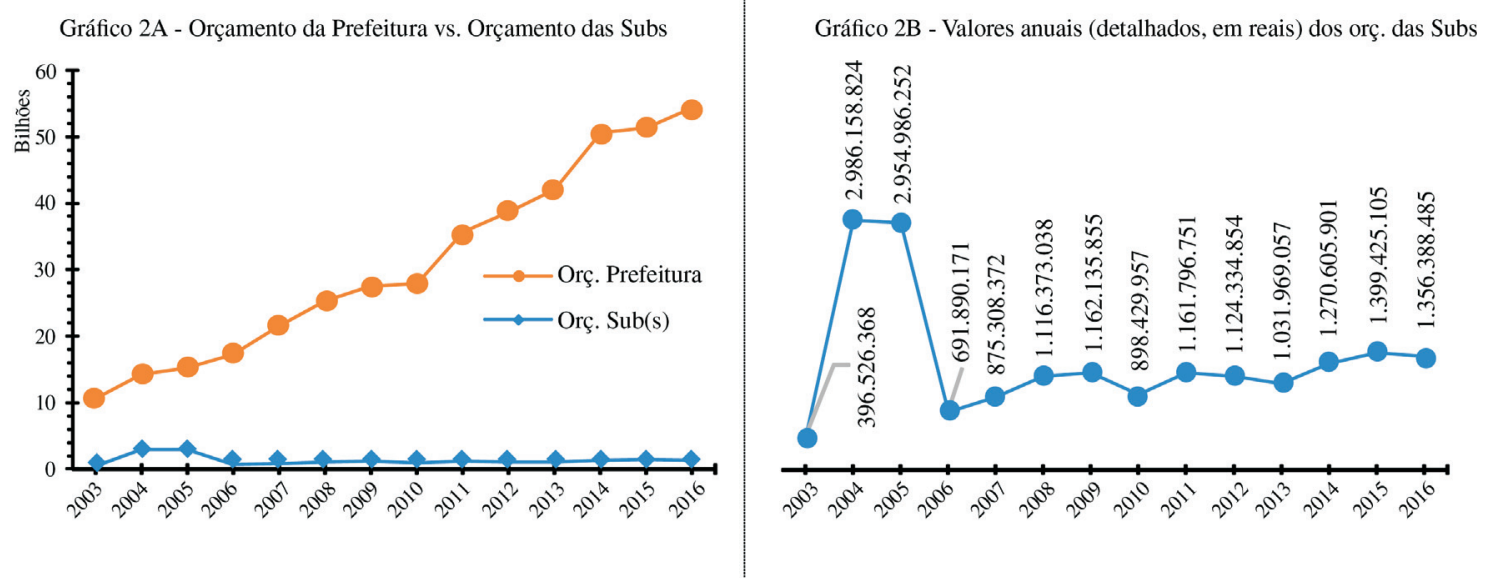

Fonte: Elaboração própria a partir das “despesas previstas” nas Leis Orçamentárias Anuais (2003-2016). Disponíveis em: http://orcamento.sf.prefeitura.sp.gov.br/orcamento/loa.php. Acesso em: 15 de dez. 2020.

tar: a dinâmica da mudança de perfis de uma gestão a outra, ou seja, de "aliados de fora" para militares da reserva. Registra a matéria que "até o término da gestão Kassab, em dezembro deste ano [2012], todos os 31 subprefeitos serão policiais militares. O último administrador civil [...] deve deixar o cargo para concorrer à prefeitura de Paranapanema, a 216 km da capital" (Pereira \& Zonta, 2012, s/p). Assim, sem critérios claros, a descentralização política tem enfrentado reviravoltas.

A gestão de Fernando Haddad não representou mudanças significativas quanto às competências e o volume de orçamento das Subprefeituras, embora tenha criado uma Subprefeitura a mais (totalizando 32) e regulamentado os conselhos de controle social locais, agora chamados de "Conselhos Participativos Municipais" (CPMs). No governo Marta houve uma tentativa, sem sucesso, de criar esses órgãos. Criados somente em 2013, esses colegiados tiveram atribuições delimitadas pelo nível territorial-administrativo de cada uma das unidades submunicipais. Eles foram formados exclusivamente por representantes da população, eleitos proporcionalmente em relação à densidade demográfica de cada um dos distritos municipais. Para a primeira gestão (janeiro de 2014 a janeiro de 2016) foram eleitos 1.133 conselheiros. Conforme sustentado por Coelho (2017 e 2020), os CPMs foram criados contendo originalidades em seu desenho institucional, pois propiciaram a ampliação dos perfis de atores que deles participam em relação ao que normalmente se verificava nos demais conselhos de políticas públicas. Dentre as inovações estão o caráter não setorial e sim territorial; a escala de abrangência das atribuições, sublocal (distritos e Subprefeituras) e não municipal; a forma de recrutamento, dada exclusivamente por eleição facultativa e sem a necessidade de o candidato estar vinculado a qualquer "segmento" ou organização; a não caracterização das instâncias como "híbridas", uma vez que não há reservas de vagas para o segmento governo ou qualquer outro, dentre outras. Apesar dessas inovações, para Coelho (2017), a principal limitação desses órgãos está associada às limitações próprias das Subprefeituras, dado o desmonte visto aqui.

Além da criação dos CPMs, o petista também tentou inovar quanto ao perfil dos subprefeitos, o que não se sustentou ao longo do tempo. Quando assumiu, Haddad 'afirmou que a 'desmilitarização' das Subprefeituras foi a primeira medida de seu governo para dar autonomia a elas". Conforme a fala do prefeito, "queremos agora empoderar politicamente as Subprefeituras para, em seguida, discutir um modelo de descentralização coerente com a legislação, mas que não 
seja tão facilmente desfeito" (Conselho Participativo Municipal terá eleições diretas em todas as Subprefeituras, 2013, s/p). Inicialmente, procurou nomear técnicos de carreira para a gestão das Subprefeituras, como engenheiros, arquitetos e urbanistas, dentre outros. Mas essas nomeações, com o transcorrer do tempo, não se sustentaram politicamente. O prefeito viu-se obrigado a ceder os cargos fora do perfil inicial em troca de apoio político.

Ao iniciar o último ano do mandato, Haddad apresentou à Câmara o Projeto de Lei $n^{\circ}$ 04/2016 do Executivo, que visava implementar a eleição dos subprefeitos pela população local. Segundo o PL, "os subprefeitos serão nomeados pelo prefeito após eleição direta, com voto facultativo em cada Subprefeitura" (São Paulo, 2016, art. $1^{\circ}$ ). Cada partido político poderia apresentar um candidato por Subprefeitura. O subprefeito poderia montar sua própria equipe e ter uma plataforma de governo local. Argumentando seguir as melhores práticas mundiais em termos de gestão de grandes cidades, propunha-se a possibilidade de concorrência ao cargo daqueles que residissem nos limites territoriais da Subprefeitura. Contemplando o "princípio da proximidade", o subprefeito deveria ser residente da localidade na qual foi eleito, o que incentivaria o debate sobre os problemas de cada bairro, geralmente ofuscado pelas questões municipais, e aproximaria as Subprefeituras dos moradores. Todavia, apresentado no apagar das luzes do governo petista, o projeto nem sequer foi pautado pelo legislativo.

Para finalizar, convém ressaltar que, para Falleti (2006), dependendo da sequência das camadas de descentralização adotadas desencadeia-se um "efeito catraca". Ou seja, uma dinâmica em que o processo de descentralização se move numa mesma direção a cada nova rodada das medidas descentralizadoras tomadas. O efeito seria de descentralização crescente. Para a autora, é a descentralização política que tem a maior potencialidade para impulsionar esse efeito. Ela salienta que "a descentralização política tem probabilidade de produzir uma política de efeito-catraca, ou seja, que move sempre na mesma direção, o que ocorre quando um grupo de partidários continua a pressionar por mais descentralização" (2006, p. 66). Para o caso da descentralização intramunicipal, em tese, esse efeito poderia ocorrer se grupos políticos nos âmbitos sublocais pressionassem por mais transferência de atribuições, recursos e poder de decisão para as unidades submunicipais. Vale ressaltar que tanto a proposta original apresentada à Assembleia Municipal Constituinte em 1990, quanto o projeto de lei de Haddad pareciam ser um passo importante nesse sentido.

Porém, o fato é que sem critérios claros a dimensão política da descentralização não se consolidou como as demais; assim, as sequências das camadas não são claras e permanecem incertas. É difícil até mesmo falar em sequência do processo. Certamente, "o movimento" não ocorreu numa mesma direção, no sentido de mais descentralização a cada nova rodada; na verdade, foi um tanto quanto desvairado. Para se valer de uma metáfora, o efeito estaria mais para uma "biruta de aeroporto" do que para uma "catraca".

Concluindo, as evidências encontradas sugerem uma longa e desvairada trajetória do processo de descentralização intramunicipal na capital paulista. $\mathrm{O}$ consenso alcançado durante a elaboração da Lei Orgânica não se consolidou, nem o esforço inicial iniciado com a aprovação da lei das Subprefeituras foi mantido. Permanecem os desafios de gestão do complexo, fragmentado e heterogêneo território municipal.

\section{Considerações finais}

O artigo procurou examinar o processo de descentralização intramunicipal na capital paulista. Para tanto, definiu o conceito em diálogo com uma literatura 
recente sobre o tema. Também buscou adaptar os termos do debate sobre os casos nacionais/subnacionais numa operação que se mostrou funcional e heuristicamente relevante para analisar o caso proposto.

Dessa forma, procuramos contribuir com as escassas investigações sobre o processo de descentralização na cidade de São Paulo, especialmente ao diminuir a lacuna das análises longitudinais de médio alcance, praticamente inexistentes sobre o caso do maior centro urbano da América Latina. Os resultados deste artigo representam um primeiro passo que merece ser continuado (explorando pontos aqui apenas tocados devido ao espaço limitado) e desdobrado em pesquisas futuras, talvez realizando análises comparativas com outras grandes cidades no mundo que adotaram a descentralização territorial como princípio governamental.

Aqui demonstrou-se que a trajetória da descentralização intramunicipal em São Paulo é longa e bastante instável. As medidas adotadas ao longo de duas décadas parecem insuficientes para garantir que os núcleos administrativos regionais tenham autonomia e protagonismo na resolução dos problemas locais. Verificou-se uma trajetória tortuosa devido à falta de consenso entre as sucessivas gestões executivas municipais - encabeçadas por distintos partidos políticos -, sobre quais deveriam ser os papeis dos órgãos regionais. Daí decorreram diversos fluxos e refluxos em torno das dimensões da descentralização, não se aplicando o "efeito catraca" (Falleti, 2006).

Nessas reviravoltas, muito recentemente foram criados os Conselhos Participativos Municipais, mecanismos institucionais de participação no âmbito de cada uma das Subprefeituras. No projeto original de criação das Subprefeituras (Montoro, 1989; Calderón, 2000; Coelho, 2017), esses conselhos tinham um papel bastante importante. Resta saber se o modo como eles foram criados, implementados e o modo como atuarão, caso consolidados, jogarão peso na dimensão política da descentralização, se adquirirão força para pressionar por mais descentralização; ou se serão apenas mais uma parte do movimento desvairado ocorrido até o momento. Mas para analisar isso, retomando Falleti, é necessário aguardar o timing de implementação da política adotada.

Rony Coelho (coelhorgs@yahoo.com.br) é doutor em Ciência Política pela Universidade Estadual de Campinas (Unicamp). Atuou como Visiting Research Fellow no Institute of Development Studies (IDS), University of Sussex (UK), através de bolsa concedida pela CAPES pelo programa de pós-doutorado no exterior.

\section{Referências}

Akerman, M. (2004) Território, governança e articulação de agendas. São Paulo: Centro de Estudos, Pesquisa e Documentação em Cidades e Municípios Saudáveis.

Arretche, M.; Vazquez, D. \& Gomes, S. (2012) Descentralização e autonomia: deslocando os termos do debate. In: A.G. Lavalle (org) O horizonte da política: questões emergentes e agendas de pesquisa. São Paulo: Editora Unesp.

Arretche, M. (1996) Mitos da descentralização: mais democracia e eficiência nas políticas públicas. Revista Brasileira de Ciências Sociais, 31(11), pp. 44-66.

Bonduki, N. \& Rolnik, R. (1982) Periferia da Grande São Paulo: reprodução do espaço como expediente de reprodução da força de trabalho. A produção capitalista da casa (e da cidade) do Brasil industrial. In: E. Maricato. A produção capitalista da casa (e da cidade) no Brasil industrial. São Paulo: Alfa-Ômega, pp. 117-154.

Borja, J. (1984) Descentralización: una cuestión de método. Revista Mexicana de Sociologia, 46(4), pp. 5-33. DOI: $10.2307 / 3540344$

Boschi, R. (1999) Descentralização, Clientelismo e Capital Social na Governança Urbana: Comparando Belo Horizonte e Salvador. Dados, 42(4), pp. 655- 690. DOI: 10.1590/S0011-52581999000400002

Caccia Bava, S. (1999) Sobre o futuro da cidade de São Paulo, descentralização e participação: subprefeituras e conselhos de representantes. Revista Serviço Social \& Sociedade, XXII(66), pp. 109-126.

Calderón, A.I. (1996) A lei orgânica paulistana e os novos mecanismos de participação popular na gestão municipal. In: $X X$ Encontro Anual da Associação Nacional de Pós-Graduação e Pesquisa em Ciências Sociais, Caxambu. 
Calderón, A.I. (2000) Democracia local e participação popular: a lei orgânica paulistana e os novos mecanismos de participação popular em questão. São Paulo: Cortez Editora, 2000.

Calderón, A.I. \& Chaia, V. (orgs) (2002) Gestão municipal: descentralização e participação popular. São Paulo, Cortez Editora.

Castells, M. \& Borja, J. (1996) As cidades como atores políticos. Revista Novos Estudos CEBRAP, 45(s/n), pp. 152-166.

Coelho, R. (2017) Os desafios de reconstrução de pedaços da cidade por meio dos Conselhos Participativos Municipais das Subprefeituras de São Paulo. Tese de doutorado. Campinas: Universidade Estadual de Campinas.

Coelho, R. (2020). A participação institucional em São Paulo: Trajetória e a experiência no governo Haddad (PT, 2013-16). Revista Brasileira de Ciência Política, s/v (31), 257-300. DOI: 10.1590/0103-335220203107

Di Giuseppe, T. (1998) A crise do planejamento urbano: uma experiência alternativa em São Paulo: o caso dos núcleos regionais de planejamento. Tese de Doutorado. São Paulo: Fundação Getúlio Vargas.

Falleti, T. (2006) Efeitos da descentralização nas relações intergovernamentais: o Brasil em perspectiva comparada. Sociologias, 8(16), pp. 46-85. DOI: 10.1590/S1517-45222006000200004

Ferreira, G.L; Borges, A. \& Ferreira, G.A.C. (2018) Vitória do improviso ou gestão da cidade? In: E.J. Grin et al. Descentralização intramunicipal nas capitais brasileiras: as políticas, a política e a participação. Rio de Janeiro: Konrad Adenauer Stiftung.

Finatec. (2004) Descentralização e poder local: a experiência das subprefeituras no município de São Paulo. São Paulo: Editora Hucitec.

Garibe, R.; Cappuci P. (orgs) (2004) Gestão Local nos territórios da cidade: ciclo de atividades com as subprefeituras. São Paulo: Secretaria das Subprefeituras.

Grin, E.J. (2018) Caminhos e descaminhos das subprefeituras na cidade de São Paulo. In: E.J. Grin, et al. Descentralização intramunicipal nas capitais brasileiras: as políticas, a política e a participação. Rio de Janeiro: Konrad Adenauer Stiftung.

Grin, E.J. et al. (2018) Descentralização intramunicipal nas capitais brasileiras: as políticas, a política e a participação. Rio de Janeiro: Konrad Adenauer Stiftung

Grin, E.J. (2011) Caminhos e descaminhos das subprefeituras na cidade de São Paulo no governo Marta Suplicy (2001-2004). Dissertação de mestrado. São Paulo: Universidade de São Paulo.

Grin, E.J. (2013) Gestão dos Territórios na cidade de São Paulo e a proposta dos conselhos de representantes no governo Marta Suplicy (2001-2004). In: $37^{\circ}$ Encontro Anual da ANPOCS, Águas de Lindóia.

Grin, E.J. (2015) Construção e desconstrução das Subprefeituras na cidade de São Paulo no governo Marta Suplicy. Revista de Sociologia e Política, 23(55), pp. 119-145. DOI: 10.1590/1678-987315235507

Grin, E.J.; Lamerão, C.R. \& Bessa, L.F. (2015) O governo das grandes cidades: uma análise comparada dos modelos de descentralização em São Paulo, Rio de Janeiro e Brasília. In: Encontro Nacional de Ensino e Pesquisa do Campo de Públicas, Brasília.

Grin, E.J; Bonivento, J.H. \& Abrucio, F.L. (2017) El gobierno de las grandes ciudades: gobernanza y descentralización em las metrópoles de América Latina. Santiago de Chile: Consejo Latinoamericano de Administración para el Desarrolho.

Harvey, D. (2012) O direito à cidade. Lutas Sociais, 29(s/n), pp. 73-89.

Hlepas, N.K. et al. (eds) (2018a) Sub-municipal governance in Europe: Decentralization beyond the municipal tier. Switzerland: Palgrave Macmillan. DOI: 10.1007/978-3-319-64725-8

Hlepas, N.K. et al. (2018b) Introduction: decentralization beyond the municipal tier. In: N.K. Hlepas et al. (eds) Sub-municipal governance in Europe: Decentralization beyond the municipal tier. Switzerland: Palgrave Macmillan. DOI: 10.1007/978-3-319-64725-8

Keinert, T.M.M. (1993) Reforma administrativa nos anos 90: o caso da prefeitura Municipal de São Paulo. Revista de Administração de Empresas, 33(4), pp. 66-81. DOI: 10.1590/S0034-75901993000400007

Kowarick, L. \& Marques, E. (2011) Introdução. In: L. Kowarick \& E. Marques (orgs) São Paulo: novos percursos e atores: sociedade, cultura e política. São Paulo: Editora 34.

Kowarick, L. (1979) A espoliação urbana. Rio de Janeiro: Paz e Terra.

Lameirão, C.R.; Cunha, D.F. \& Tôrres, R.M. (2018) Apenas uma miragem: a inconclusa implementação das Administrações Regionais em Goiânia. In: E.J. Grin et al. Descentralização intramunicipal nas capitais brasileiras: as políticas, a política e a participação. Rio de Janeiro: Konrad Adenauer Stiftung.

Lowndess, V. \& Sullivan, H. (2008) How Low Can You Go? Rationales and Challenges for Neighbourhood Governance. Public Administration, 86(1), pp. 53-74. DOI: 10.1111/j.1467-9299.2007.00696.x

Martinelli B. \& Olivieri, C. (2015) Descentralização Intramunicipal: Trajetória e articulação entre política e administração nos municípios de São Paulo e Rio de Janeiro. Iniciação Científica Cesumar, 17(1), pp. 63-76.

Martins, M.L.R. (1997) Descentralização e subprefeituras experiência da gestão 1989-1992: Prefeita Luiza Erundina de Sousa, mímeo.

Montoro, A.F. (1989) Participação: Desenvolvimento com democracia. São Paulo: Nossa Editora.

Moya, M.E. (2011) Os estudos sobre a cidade: quarenta anos de mudança nos olhares sobre a cidade e o social. In: L. Kowarick \& E. Marques (orgs) São Paulo: novos percursos e atores: sociedade, cultura e política. São Paulo: Editora 34.

Nunes, E. (1996) Poder local, descentralização e democratização: um encontro difícil. São Paulo em Perspectiva, 10(3), pp. 32-39. 
Pinheiro, J. (1999) Máfia da Propina: caso de polícia ou questão política?Lutas Sociais. s/v(6), pp. 97-110.

Pólo, E. et al. (2005) Descentralização Administrativa da Cidade de São Paulo: Um Estudo de Caso. In: XXIX Encontro da Associação Nacional de Pesquisa em Administração, Brasília

Sadek. M.T. (1991) Poder local: perspectivas da nova ordem constitucional. São Paulo em Perspectiva, 5(2), pp. 9-15.

Santos, U.P. \& Barreta, D. (2004) As subprefeituras de São Paulo. São Paulo: Editora Hucitec.

Scarfoni Filho, F. (1981) O processo de descentralização na prefeitura de São Paulo: o caso das administrações regionais. Dissertação de Mestrado. São Paulo: Fundação Getúlio Vargas.

Shah, A. \& Thompson, T. (2004) Implementing decentralized local governance: a treacherous road with potholes, detours, and road closures. Working Paper no. 3353, Washington D.C: World Bank.

Souza, C. (1996) Reinventando o poder local: limites e possibilidades do federalismo e da descentralização. São Paulo em Perspectiva, 1(3), pp. 103-112.

Souza, C. (2001) Federalismo e descentralização na Constituição de 1988: processo decisório, conflitos e alianças. Dados, 44(3), pp. 513-560. DOI: 10.1590/S0011-52582001000300003

Souza, C. (2004) Governos locais e gestão de políticas sociais universais. São Paulo em Perspectiva, 18(2), pp. 27-41. DOI: $10.1590 /$ S0102-88392004000200004

Sposati, A.O. (2001) Cidade em pedaços. São Paulo: Editora Brasiliense.

Swianiewicz, P. (2015) Intra-municipal units in urban political systems in Poland: vicious roundabout of marginalization or dead-end street? Journal of Public Administration and Policy, 7(2), pp. 173-198. DOI: 10.2478/nispa-2014-0008

Van Ostaaijen, J., et al. (2012) The added value of intra-municipal decentralization: comparing Bologna, Rotterdam and Birmingham. In: L. Schaap \& H. Daemen (eds) Renewal in european local democracies. Wiesbaden: Springer, pp. $145-164$.

\section{Outras fontes}

Conselho Participativo Municipal terá eleições diretas em todas as subprefeituras. (2013) SEC - Secretaria Executiva de Comunicação da Prefeitura. São Paulo, 01 ago. Disponível em: https://www.nossasaopaulo.org.br/2013/08/02/conselho-participativo-municial-tera-eleicoes-diretas-em-todas-as-subpr efeituras/. Acesso em: 28 nov. 2020.

Antunes, C. (s/d) Retrocesso na descentralização administrativa municipal. [online] Site da Escola de Governo de São Paulo. São Paulo. Disponível em: http://www.escoladegoverno.org.br/artigos/222-retrocesso-descentralizacao. Acesso em: 17 jul. 2016.

São Paulo (1990) Lei Orgânica do Município de São Paulo. Disponível em: https://www.prefeitura.sp.gov.br/cidade/secretarias/upload/educacao/cme/LOM.pdf. Acesso em: 08 de dez. 2020.

São Paulo (2002) Lei $n^{o}$ 13.399/2002. Dispõe sobre a criação de Subprefeituras no Município de São Paulo, e dá outras providências. Disponível em: https://www.prefeitura.sp.gov.br/cidade/upload/lei_13_399_1254940922.pdf. Acesso em: 08 de dez. 2020.

São Paulo (2016) Projeto de lei $n^{o}$ 04/2016 do Executivo. Altera a lei $n^{o} 13.399$, de $1^{o}$ de agosto de 2002, que dispõe sobre a criação de subprefeituras no município de São Paulo, para determinar a eleição direta para subprefeito. Disponível em: http://documentacao.camara.sp.gov.br/iah/fulltext/projeto/PL0004-2016.pdf. Acesso em: 14 de dez. 2020.

Pereira E. \& Zonta, N. (2012) Subprefeitos ou superzeladores?. Folha de S. Paulo. São Paulo, 30 jan. Disponível em: https://www.nossasaopaulo.org.br/2012/01/30/subprefeitos-ou-superzeladores-folha-de-s-paulo/. Acesso em: 16 jul. 2016. 


\section{The intra-municipal decentralization process in São Paulo}

ABSTRACT Introduction: The governance of large urban centers has become a growing contemporary challenge. In São Paulo, structural problems have left profound marks on the social-urban land. Aiming at a political-administrative model for a highly complex territory, the decision to decentralize the municipal administration was fixed in the Organic Law of the Municipality, in 1990. This article aims to examine this process of intra-municipal decentralization in the city in its three dimensions: political, administrative and fiscal. The article analyzes the mechanisms created for territorial governance, extending the analysis to the last government finalized in the city (Haddad, 2013-16). Materials and methods: The research is qualitative and adopts "procedural analysis" as a theoretical and methodological perspective. Accordingly, decentralization is a set of measures and reforms adopted in layers over time. The article mainly uses documentary analysis (legislation) and bibliographic references, which are lacking in relation to a theme in Brazil. He seeks to adapt, heuristically, the terms of the debate on decentralization from national / subnational levels to municipal / intra-municipal levels in order to contemplate the case. Results: The evidence found suggests a long, discontinuous and erratic trajectory of the decentralization process in the city. Therefore, the "ratchet effect" described in the literature does not apply. In this effect, the various layers of the decentralization processes take place sequentially and following the same direction for each new round. In São Paulo, due to a non-consensual process between the different municipal governments about what the roles of the sub-municipal bodies should be, the decentralization process has faced several twists and turns. Discussion: The article seeks to add efforts to the expansion of knowledge about the process of sub-municipal governance in the largest city in Latin America, especially when operationalizing a longitudinal mid-range analysis, and risking, in dialogue with both national and international literature, a definition for intra-municipal decentralization, although the research is incipient.

KEYWORDS: intramunicipal decentralization; sub-municipal governance; municipal administration; São Paulo; boroughs.

This is an Open Access article distributed under the terms of the Creative Commons Attribution Non-Commercial License which permits unrestricted non-commercial use, distribution, and reproduction in any medium provided the original work is properly cited.

A produção desse manuscrito foi viabilizada através do patrocínio fornecido pelo Centro Universitário Internacional Uninter à Revista de Sociologia e Política. 